\section{INTRODUCTION TO GUEST EDITOR}

\section{James F. Thornton, M.D.}

James F. Thornton, M.D., is an associate professor in the Department of Plastic Surgery at the University of Texas Southwestern Medical Center in Dallas, Texas. Dr. Thornton received his medical degree from the University of Texas Southwestern Medical Center and also completed a 5-year residency in general surgery there. Under the guidance of Dr. John Bostwick at Emory University in Atlanta, Georgia, Dr. Thornton completed his plastic and reconstructive surgery training.

Dr. Thornton is board certified by the American Board of Plastic Surgery and is a Fellow of the
American College of Surgeons. He is an active member of numerous plastic surgery organizations, and he lectures locally and nationally about plastic and reconstructive surgery. Dr. Thornton's special interest is Mohs reconstruction, an area in which he currently has one of the largest practices in the nation. He has put together an excellent group of experts for this issue, which will serve as a reference for some time to come.

Larry H. Hollier, Jr., M.D., ${ }^{1,2}$ Editor-in-Chief
${ }^{1}$ Department of Dermatology, Baylor College of Medicine, Houston, Texas; ${ }^{2}$ Ben Taub General Hospital, Houston, Texas.

Address for correspondence and reprint requests: Larry H. Hollier, Jr., M.D., F.A.C.S., Chief of Service, Ben Taub General Hospital, 1709 Dryden, Suite 1600, Houston, TX 77030.

Soft Tissue Facial Reconstruction; Guest Editor, James F.
Thornton, M.D.

Semin Plast Surg 2008;22:243-244. Copyright (C) 2008 by Thieme Medical Publishers, Inc., 333 Seventh Avenue, New York, NY 10001, USA. Tel: +1(212) 584-4662.

DOI 10.1055/s-0028-1095882. ISSN 1535-2188. 